\title{
A methodological review of studies of SALT (Suggestive-accelerative learning and teaching) techniques
}

\author{
B. Dipamo and R. F. S. Job \\ University of Sydney
}

\begin{abstract}
Suggestopedia and SALT techniques are being applied in the adult education, business training and consulting spheres. However, a review of the relevant literature reveals doubtful support. Evaluative studies are often methodologically flawed, and the results are often inconsistent. Overall, the results do not justify the claims made about the systems. However, factors such as subject anxiety and duration of the study may explain some inconsistencies.
\end{abstract}

Evaluations of individual components of the systems suggest that some components (visualisation, breathing, and music) are potentially fruitful, and deserve further investigation. Nonetheless, application to the business and consulting sector may by restricted by poor the results generally obtained in short-term teaching programs.

Advances in technology in recent years have led to an information expansion of unparalleled dimensions. The demand for business people and students to encode and retain information quickly and efficiently has increased proportionally with this expansion. Furthermore, growth in minority populations and international business contacts have made the acquisition of a second language highly desirable. Therefore, the introduction of a system which claims to provide the practical means of achieving these goals deserves careful evaluation, using rigorous, unbiased, scientific techniques.

"Suggestopedia" is a system of suggestive-accelerative learning and teaching techniques professing such a claim. Suggestopedia was developed by Georgi Lozanov, a Bulgarian educator and psychiatrist and was originally introduced as an intensive, foreign language teaching 
program. Lozanov claims that a $1,000 \%$ increase in learning is possible with Suggestopedia (Lozanov, 1978). In recent years elements of Suggestopedia have been adopted for accelerated learning of a wide variety of materials. Increasingly, Suggestopedia, and its North American adaptation SALT, an acronym for "System of accelerative learning and teaching", are being used in schools and colleges in Europe and North America (Scovel, 1979). Recently, similar systems have been promoted in both public education and the business sector in Australia.

The present paper outlines the methods employed in suggestopedia, reviews factors likely to influence suggestopedia's effectiveness, and reviews evidence for its effectiveness.

\section{Accelerative Learning Techniques}

Suggestopedia consists of many component parts, ie. suggestion, authority (prestige), communication (verbal and non-verbal), intonation and rhythm of presentation, breathing synchronised with presentation, relaxation, "mind-calming", mental imagery, subliminal stimuli and active role playing (Racle 1976; Schuster \& Gritton, 1986). Suggestopedia is based partly on the concept of suggestion, that much of what we learn is not by direct verbal instruction but by direct and indirect non-verbal cues. Lozanov emphasises the importance of the physical environment and the possible influence of subliminal messages which exist in every setting (Scovel, 1979). Non-verbal cues, such as body language, expressiveness, eye-contact and facial expressions are key elements in interactions between people. The ability to effectively utilise these cues is known to influence the level of communication (Baron \& Byrne, 1984).

Each Suggestopedia lesson starts by creating an expectancy that learning will be easy and fun. Students are exposed to music, posters on the wall depicting scenes relevant to the task, given affirmations to do or reminded of how well they did last time. In order to boost self-esteem, students learning a foreign language are often given another identity and name. The teacher creates an atmosphere where learning expectancy is enhanced. The fact that teacher expectancy has a substantial impact on how well students learn is well established (Rosenthal \& Jacobson, 1968). This is a form of "placebo" effect and something Lozanov (1978) actively utilised.

The material to be learned is presented in three forms: first, an active presentation in which the material is vividly presented by means of visual images, association cues and dynamic vocal intonation (three voice levels are used: loud/commanding, normal and soft/whispering). Second, a passive form in which students sit relaxed, with eyes closed and breathing synchronised with baroque music which plays in the background. The teacher reviews the lesson, again using oral intonation. In the third 
session, students enact a dramatic presentation of the lesson content and practice until some level of proficiency is achieved. A self-correcting quiz normally ends the lesson (Palmer, 1985).

Research into Suggestopedia, particularly in North America, has focused on isolating so called "critical" elements, in order that these elements may be implemented in the conventional classroom. This focus has been largely on relaxation training and music, although it has been claimed there is ample evidence already available to indicate these techniques, on their own, do not accelerate learning (Alexander, 1982). The first SALT technique to be examined will be relaxation, each major technique will be evaluated in turn.

\section{Relaxation}

An examination of the SALT literature revealed that in studies where relaxation is a major independent variable, rather than just one element of SALT or Suggestopedia, only one study indicated a clear improvement in performance for the experimental group over the control group (Johnson, 1982). However, one study also produced a negative effect. (See Table 1 for a summary of the relevant studies).

Table 1: The results of studies utilising relaxation as a major independent variable

\begin{tabular}{|c|c|c|c|c|}
\hline Study & $\begin{array}{c}\text { Major } \\
\text { independent } \\
\text { variables }\end{array}$ & $\begin{array}{l}\text { Control } \\
\text { group }\end{array}$ & $\begin{array}{l}\text { Random } \\
\text { allocation }\end{array}$ & Results \\
\hline $\begin{array}{l}\text { Biggers \& Stricherz, } \\
1976\end{array}$ & Relaxation & yes & yes & Negative effect \\
\hline $\begin{array}{l}\text { Martin \& Schuster, } \\
1977\end{array}$ & $\begin{array}{l}\text { Relaxation and } \\
\text { tension induction }\end{array}$ & yes & yes & $\begin{array}{l}\text { No significant } \\
\text { difference }\end{array}$ \\
\hline Alexander, 1982 & Relaxation, music & no & no & $\begin{array}{l}\text { No significant } \\
\text { difference }\end{array}$ \\
\hline Gamble et al., 1982 & Relaxation, music & yes & yes & Limited support \\
\hline Johnson, 1982 & Relaxation & yes & yes & Positive effect \\
\hline $\begin{array}{l}\text { Wagner \& Tilney, } \\
1983\end{array}$ & $\begin{array}{l}\text { Relaxation, music, } \\
\text { "mind-calming" }\end{array}$ & yes & yes & $\begin{array}{l}\text { No significant } \\
\text { effect }\end{array}$ \\
\hline $\begin{array}{l}\text { Render, Hall \& } \\
\text { Moon, } 1984\end{array}$ & Relaxation, music & yes & yes & $\begin{array}{l}\text { No significant } \\
\text { effect }\end{array}$ \\
\hline Zeiss, 1984 & $\begin{array}{l}\text { Relaxation, music } \\
\text { oral intonation }\end{array}$ & yes & yes & Limited support \\
\hline
\end{tabular}




\section{Music}

When music is a major independent variable in accelerated learning studies, the literature is again somewhat equivocal. Of the nine studies examined, four achieved significant increases in performance while the remaining studies demonstrated no clear advantage with music (see Table 2). Three of the four experiments which indicated a beneficial effect of music used control groups and random allocation of subjects. The uncontrolled studies (Schuster \& Vincent, 1980; Alexander, 1982) are not useful in assessing the effect of music.

Table 2: The results of studies utilising music as a major independent variable

\begin{tabular}{|c|c|c|c|c|}
\hline Study & $\begin{array}{l}\text { Major independent } \\
\text { variables }\end{array}$ & $\begin{array}{l}\text { Control } \\
\text { group }\end{array}$ & $\begin{array}{l}\text { Random } \\
\text { allocation }\end{array}$ & Results \\
\hline $\begin{array}{l}\text { Bordon \& Schuster, } \\
1976\end{array}$ & $\begin{array}{l}\text { Music, breathing, } \\
\text { suggestion, positive } \\
\text { atmosphere }\end{array}$ & yes & yes & Positive effect \\
\hline $\begin{array}{l}\text { Schuster \& Vincent, } \\
1980\end{array}$ & Music & no & no & Positive effect \\
\hline Alexander, 1982 & Music, relaxation & no & no & $\begin{array}{l}\text { No significant } \\
\text { effect }\end{array}$ \\
\hline Gamble et al., 1982 & Music, relaxation & yes & yes & $\begin{array}{l}\text { No significant } \\
\text { effect }\end{array}$ \\
\hline $\begin{array}{l}\text { Schuster \& Mouzon, } \\
1982\end{array}$ & Music, suggestion & yes & yes & Positive effect \\
\hline Stein et al., 1982 & Music, imagery & yes & yes & $\begin{array}{l}\text { No significant } \\
\text { effect }\end{array}$ \\
\hline $\begin{array}{l}\text { Wagner \& Tilney, } \\
1983\end{array}$ & Music, relaxation & yes & yes & $\begin{array}{l}\text { No significant } \\
\text { effect }\end{array}$ \\
\hline Render et al., 1984 & Music, relaxation & yes & yes & $\begin{array}{l}\text { No significant } \\
\text { effect }\end{array}$ \\
\hline Zeiss, 1984 & $\begin{array}{l}\text { Music, relaxation, } \\
\text { oral intonation }\end{array}$ & yes & yes & $\begin{array}{l}\text { No significant } \\
\text { effect }\end{array}$ \\
\hline
\end{tabular}

\section{Suggestion}

There are difficulties in the short-term studies in creating the conditions required by many of the more subtle components of Suggestopedia. SALT research has tended to focus more on the mechanical aspects of accelerated learning, such as music, relaxation and mental imagery which are easily understood and implemented. Other aspects such as suggestion, subliminal stimuli, and non-verbal cues are often neglected. Given the emphasis Lozanov places on suggestion, it is surprising that very few studies have examined this variable. There are only two studies available in which suggestion is used as an independent variable (Schuster \& Mouzon, 1982; and Schuster \& Martin, 1980). 
Schuster \& Miller (1979) commented that they had not utilised suggestion because it takes time to produce change in belief systems and attitudes. Despite this, Schuster \& Mouzon (1982) introduced suggestion in the form of a printed, two sentence paragraph. Subjects in this study performed better when given the suggestion that the material was hard to learn, than when told it was easy to learn. This is the opposite effect to that which Schuster \& Mouzon's and Lozanov's position had predicted. It may be that subjects, given the suggestion the material would be easy to learn, who find in reality it is difficult, and feel frustrated or inadequate on the task. In contrast, subjects who are told the material is hard to learn have less fear of failure (because failure would be attributable to the task not the subject). This may improve their performance. If this is an appropriate interpretation it would seem to be an inevitable risk in Lazanov's view that we should suggest to learners that the task is easy.

In the Schuster \& Martin (1980) experiment, a more sophisticated form of suggestion was used: "early pleasant learning restimulation" (EPLR), a Gestalt reintegrative technique that focuses on the bodily feelings, sensations, emotions and thoughts associated with an early pleasant experience. Subjects given no suggestion and a difficult task performed better than the group given EPLR and a difficult task. With no suggestion and an easy task, the difference between the two groups was insignificant. Thus, again the results do not support Lazanov's position.

\section{Visualisation}

While visualisation is not usually treated as an individual element in SALT as music and relaxation are, it nevertheless plays an important role. Visualisation is commonly used in two forms. First, in mind-calming exercises subjects are given guided fantasy journeys to reduce psychological anxiety. Second, visualisation is used to create mental images associating the material to be learned.

There is extensive evidence on mental imagery (cf Paivio, 1971), usually with paired associate words, where subjects learn an association between a stimulus word and a response word and then attempt to recall the response when cued with the stimulus. Mental imagery, in which images are created by the subjects of the stimulus and response words interacting in some manner, have been shown to increase recall by between $1 \backslash(12-3$ times (Bower 1972; Paivio, 1971). No validated study using SALT or Suggestopedia, short or long term known to the present authors, has reported increases in performance greater than $300 \%$, despite Lozanov's (1978) claim that tenfold increases in performance are possible. Therefore mental imagery alone could account for the improvements sometimes seen in Suggestopedia since it appears to result in increases of similar magnitude. 


\section{Synchronised Breathing}

Shaffer (1979) offered the argument that deep breathing was the critical factor in accelerated learning and the reason why so many studies had failed to achieve hypermnesia (exact memory). The claim is supported by evidence that in Lozanov's early work, before his government clamped down on information, breathing techniques figured prominently. In recent years, rhythmic breathing has received little attention.

Lozanov found that to achieve the appropriate combination of relaxation, concentration, slow pulse rate and alpha state in which accelerated learning was possible, yogic exercises and breathing were required (Bancroft, 1976). Hyperventilation, according to Shaffer (1979), lowers the carbon dioxide concentration of the blood and raises the $\mathrm{pH}$ (alkaline concentration) of the blood and body fluids, thereby increasing the excitability of the nerve cells. Experiments in altered learning through carbon dioxide-induced disruption show that this compound acts upon short term memory (STM) rather than long-term memory (LTM) (Waterlain, 1970; van Eys, Rigter \& Leonard, 1975). Voluntary hyperventilation through rhythmic breathing reduces carbon dioxide levels, thus enhancing STM, allowing more information to be moved into LTM (Shaffer, 1979).

Rhythmic breathing, like many other component parts of Suggestopedia, has not been used, or tested, in isolation. Thus, despite a known possible mechanism of action, the practical impact of this component has not been established.

\section{Active Presentation}

It is well established that material which is presented vividly is more likely to be remembered (Baron \& Byrne, 1984). Suggestopedia utilises this fact by playing active, lively classical music, using oral intonation such that one moment the teacher is loudly speaking the material, the next softly whispering it so that students have to listen carefully. Mental imagery is utilised to create vivid pictures and associations. For example in learning German, the German word and its meaning can be associated by interacting objects. The mnemonic keyword method employs a keyword which links a foreign word to its English translation by mental imagery.

\section{Passive Review}

In the passive music review subjects sit relaxed, with eyes closed. Soft baroque music plays in the background. The music is specifically chosen for its $40-60$ beats per minute. This is hypothesised to lower heartbeat and blood pressure and induce an alpha state in which learning is accelerated 
(Ostrander \& Schroeder, 1979). The material is presented for four seconds, then there is a pause for four seconds. Subjects hold their breath while the material is presented and breathe out and in during the pause. The teacher presents the same material, once again using oral intonation. Students are encouraged to recall the visualisations and associations they made in the active presentation.

\section{Dramatic Enactment}

In the third and last session, students enact a dramatic presentation of the material. In foreign language learning students commonly form groups and role play the material. Once students have reached the required level of proficiency or at the lesson end, students complete a self-correcting quiz in order to assess how much they have learned. This normally concludes a Suggestopedia class.

\section{"Superlearning" Techniques}

Superlearning techniques utilise many of the elements outlined above. Schuster \& Gritton (1986) have criticised Superlearning on the basis that it is not Suggestopedia, and that failures of Superlearning should not reflect on Lozanov's system. This argument seems uncompelling since Superlearning is based on Lozanov's methods, as are SALT methods. In fact the Superlearning format of accelerative learning techniques follows Lozanov's system more closely than many of the SALT experiments. Applegate (1983) used Superlearning techniques with great success, as Schuster \& Gritton (1986) were quick to note. If failure of Superlearning should not reflect on Suggestopedia, then neither should success.

Three studies were examined which utilised Superlearning techniques (Wagner \& Tilney, 1983; Applegate, 1983 as reported by Schuster \& Gritton, 1986; and Zeiss, 1984). While significant results were sometimes reported, fatal methodological flaws exist in two of the three studies.

The Applegate (1983) study was a two year long project which utilised Superlearning techniques to learn reading, maths, spelling and writing. Students ranged from learning disabled to gifted and talented. The experimental groups achieved a significant increase over the control groups averaging 13. 5\% (in Schuster \& Gritton, 1986). Unfortunately methodological problems are apparent even from Schuster \& Gritton's review. In the experimental group each teacher had an average of 27 students per class. In the control group each teacher had an average of 43 students. Clearly then, management and control of the smaller classes would be much easier and students in the experimental group could be given more individual attention and tuition .

Wagner \& Tilney (1983) did not equate the experimental and control groups for relaxation time in the experiment. 
Zeiss (1984) reported results suggestive of improved learning under one combination of superlearning procedures. However, the extent of the improvement is uncertain due to a "ceiling" effect (a number of subjects reached $100 \%$ performance). Therefore, in this case, potentially positive effects may have been masked.

\section{Factors influencing the outcome of SALT studies}

The following section considers factors often apparently extraneous to the particular studies, which may nonetheless influence their outcome.

\section{Duration of Study}

SALT studies and Suggestopedia programs vary in length from 14 minute experiments (Stein, et al., 1982) to two year projects (Applegate, 1983). There is no datum on the effects of intensive, continuous use of Suggestopedic methods other than Lozanov's data and these are incomplete (Scovel, 1979). An examination of the SALT literature may provide an indication of the effect length of study has on results. The relevant studies are summarised in Table 3.

The results in Table 3 suggest that these methods are effective with longer term use. As students acclimatise to SALT methods and teachers become more proficient in their use, there is an overall increase in subject performance. Alternatively, these results may reflect the conviction/ commitment to the method and the study required by both teacher and student. Such conviction is likely to produce substantial experimenter demand characteristics which could by themselves produce the results observed. Furthermore, the length of the study is confounded with the experience of the teacher, as can be seen in Table 3 .

The difficulty is in separating out these demand effects which Lozanov intentionally utilised (and which could be used without Suggestopedia) from the effects of the "mechanical" aspects of SALT, ie. music, relaxation, oral intonation and so on.

\section{Instructor Experience}

It is often difficult to gauge the experience of the teacher or experimenter from the literature. Early evaluations of Lozanov's data stressed the importance of instructor experience and strict application of the methods. However, SALT studies have since sometimes demonstrated that music and imagery can increase learning even when subjects read printed material with no instructor involvement (Stein, et al., 1982). Schuster \& Mouzon (1982) used music as the main independent variable and achieved 
Table 3: Comparison of studies with short, medium and long term duration/instructor experience

\begin{tabular}{|c|c|c|c|c|c|}
\hline Study & $\begin{array}{l}\text { Study } \\
\text { duration }\end{array}$ & $\begin{array}{c}\text { Known SALT } \\
\text { experience }\end{array}$ & $\begin{array}{l}\text { Control } \\
\text { group }\end{array}$ & $\begin{array}{c}\text { Random } \\
\text { allocation }\end{array}$ & Results \\
\hline \multicolumn{6}{|l|}{ SHORT TERM } \\
\hline Stein et al, 1982 & $14 \mathrm{~min}$. & no & yes & yes & Positive effect \\
\hline Alexander, 1982 & $30 \mathrm{~min}$. & no & yes & yes & $\begin{array}{l}\text { No significant } \\
\text { effect }\end{array}$ \\
\hline Render et al., 1984 & $60 \mathrm{~min}$. & no & yes & yes & $\begin{array}{l}\text { No significant } \\
\text { effect }\end{array}$ \\
\hline $\begin{array}{l}\text { Schuster \& Martin, } \\
1979\end{array}$ & $70 \mathrm{~min}$. & yes/no & yes & yes & $\begin{array}{l}\text { No significant } \\
\text { effect }\end{array}$ \\
\hline $\begin{array}{l}\text { Schuster \& } \\
\text { Mouzon, } 1982\end{array}$ & $81 \mathrm{~min}$. & no & yes & yes & Positive effect \\
\hline \multicolumn{6}{|l|}{ MEDIUM TERM } \\
\hline Zeiss, 1984 & 3 weeks & no & yes & yes & Positive effect \\
\hline Johnson, 1982 & 4 weeks & no & yes & yes & Positive effect \\
\hline $\begin{array}{l}\text { Wagner \& Tilney, } \\
1983\end{array}$ & 5 weeks & no & yes & yes & $\begin{array}{l}\text { No significant } \\
\text { effect }\end{array}$ \\
\hline Gamble et al., 1982 & 5 weeks & yes & yes & yes & Positive effect \\
\hline $\begin{array}{l}\text { Bordon \& } \\
\text { Schuster, } 1976\end{array}$ & 6 weeks & yes & yes & yes & Positive effect \\
\hline \multicolumn{6}{|l|}{ LONG TERM } \\
\hline Schuster \& Vincent & $1 \mathrm{yr}$. & yes & no & no & Positive effect \\
\hline $\begin{array}{l}\text { Gassner-Roberts \& } \\
\text { Brislan, } 1984\end{array}$ & $1 \mathrm{yr}$. & yes & yes & yes & Positive effect \\
\hline Applegate, 1983 & 2 yrs. & yes & yes & yes & Positive effect \\
\hline
\end{tabular}

$24 \%$ higher performance on acquisition and $26 \%$ higher on retention. According to the literature, Mouzon was inexperienced with SALT methods and was carrying out the experiment under Schuster's supervision. There is then evidence that inexperienced experimenters, using easily applicable techniques such as music, can achieve accelerated learning.

When more complex techniques are involved, however, it is suggested that experimenter experience appears to become an important variable. An example of this is offered by Schuster \& Miller (1979). In this controlled, laboratory experiment, Schuster, a highly experienced pioneer in SALT methods, and Miller, an inexperienced student, each ran half the subjects. Miller was apparently naive as to previous SALT literature and sceptical as to the experimental outcome (Schuster \& Miller, 1979). With active presentation versus no active presentation, Schuster's male subjects 
performed significantly better, while Miller's performed significantly worse. Female subjects showed no significant difference with active presentation With music review, where subjects hear the material a second time accompanied by baroque music, versus no music review and practising alone or in pairs, Miller's male subjects who were practising alone performed significantly worse, while Schuster's performed significantly better. Schuster's female subjects again showed no significant difference in contrast to Miller's female subjects who performed significantly worse in pairs and significantly better alone. (Of course, differences between Miller and Schuster other than experience may account for these results. For example, Schuster's conviction may be expected to create more experimental demand than Miller's scepticism.)

While Schuster and Miller used "experimenter" as an independent variable, there appears great reluctance within the study to accept the results of this variable. Rather than granting that experimenter inexperience (or conviction) contributed to results contrary to expectation, the authors comment that, though active presentation for males was significantly lower for one experimenter, this effect was felt to be minor. The same comment follows the results of music review, with the additional reflection that music review was generally hypothesised to be superior. Yet the data simply did not substantiate this assertion. There were no significant differences between subjects given music review and subjects given no music review, whether male or female. In fact, the overall mean for subjects with music review was lower than for subjects without music review. However, the authors do acknowledge that "subtle demand characteristics of the two experimenters may be responsible for these differences" (Schuster \& Miller, 1979, p.45).

An examination of available individual studies revealed that in five studies where the instructor is known to be experienced in SALT methods, all achieved significant gains in performance for the treatment group (see Table 3). However, this may reflect experimenter demand, confounded with study duration, or methodological flaws (see later discussion).

\section{Anxiety}

Two studies have focused on the effects of anxiety on performance in relation to Suggestopedia (Martin \& Schuster, 1977 and Schuster \& Martin, 1980). Since the 1977 study acted as a pilot study for the more comprehensive 1980 experiment, the focus will be on the latter. Schuster \& Martin (1980) found that subjects high in trait anxiety performed best when tensed in the learning situation, while subjects low in trait anxiety performed best when relaxed. Thus trait-state matching occurred (ie. high anxiety subjects may have become accustomed to high anxiety and so may learn efficiently in this state. Thus, changing their state may disrupt their 
usual learning abilities). This is apparently contrary to the bulk of the literature which indicates that high anxiety is the least conducive state for learning (Ferguson, 1976). This would seem to suggest then, that relaxation would not benefit all subjects equally and may in fact impair the performance of high anxiety subjects.

\section{Overview of reported results}

As can be seen from the earlier discussion, many studies report no significant superiority of various parts of the Suggestopedic method. Some studies report impairment, while some report clear improvement. For practical purposes the magnitude of the improvements observed must be considered.

Even when enhanced learning or retention is reported the differences are often meagre: 9\% (Gassner-Roberts \& Brislan, 1984); 13.5\% (see Schuster \& Gritton, 1986). However, differences as large as $250 \%$ have been reported (Bordon \& Schuster, 1976). Such differences could be accounted for purely in terms of the imagery part of the technique, since imagery has been shown to produce improvements of 150-300\% (Bower, 1972; Paivio, 1971). The data do not support Lozanov's claimed 1000\% improvement (Scovel, 1979). However the data do suggest that the technique can produce improvements under certain circumstances, perhaps largely due to the use of imagery. Nonetheless, many studies reporting significant effects contain critical methodological problems which render their results ambiguous, as reviewed in the next section.

\section{Methodology}

Many of the studies examined lacked control groups and did not randomly allocate subjects (Alexander, 1982; Schuster \& Vincent, 1980). Pre- and Posttests were the only method used to measure progress (e. g. Schuster \& Vincent, 1980). This is unsatisfactory since the amount of progress under a different technique is not known. The generally poor methodology is highlighted by Palmer's (1985) review. Of the 42 SALT experiments reviewed by Palmer (1985), 25 studies had no control group, five gave only anecdotal progress reports, three were case studies, and in two studies where a control group was used, subjects were not randomly assigned. Of the ten experimental groups which were methodologically sound, five resulted in no significant difference between control and experimental groups (e. g. Held, 1976; Caskey, 1976; Schulz, 1978; Lee, 1981; Hales, 1983 in Palmer, 1985). In the five other studies the experimental group performed significantly better than the control group (Schuster \& Ginn, 1978; Schuster \& Pritchard, 1978; Pritchard, Schuster \& Walker, 1979; Nelson, 1979; Galyean, 1980 in Palmer, 1985). The invalidity 
of the methodology in many of the studies renders their conclusions suspect. Only through exacting scientific methods can an unbiased evaluation of SALT techniques be reached. The various ways in which studies can fail to achieve the required scientific rigour are reviewed below.

\section{Allocation of the subjects}

An analysis of a one year evaluative study undertaken at the University of Adelaide, which used Suggestopedia to teach German to first year students, illustrates the difficulty in separating cause from effect (GassnerRoberts \& Brislan, 1984). A detailed analysis of this study follows since it exemplifies a number of critical methodological problems. A review of this study by Schuster \& Gritton (1986) concluded that the considerable data available confirmed the superiority of Suggestopedia over conventional learning and teaching methods. A close examination of the study, however, calls this conclusion into question.

The study employed three groups, an experimental group (EG), and two control groups, one a day class (CG-D), the other an evening class (CG-E). Flaws in allocation of students and the arrangements made for the three groups are apparent. From the pool of 46 students enrolled in the course, 22 were day students. This constituted the CG-D. The other 24 students were evening students and subjects were allocated at random to the EG and CG-E. There are a number of problems with these arrangements. First, the CG-D consisted of 22 students compared to the 12 students in both the CG-E and the EG. It is possible that students in the smaller groups received more individual tuition than the CG-D students. Second, the experience of students, both in German and other languages, was not taken into account in the allocation of subjects. Six students in both CG-E and EG had studied another language and in the EG, four students had previously studied German. In the CO-E, one student had matriculated in German and another had lived in Germany for two years. Four others had undertaken previous German language studies. Third, many differences may exist between day and evening students. Under the circumstances, matched allocation would have been superior and equal class size was essential.

\section{Group arrangements/Subject expectancy}

Other difficulties arise from tile arrangements made for the experimental group (EG) in the above study. While the control groups met in an ordinary classroom, the EG met in the teacher's staff room, "where relaxed seating could be arranged and an informal atmosphere achieved as recommended" (Gassner-Roberts \& Brislan, 1984, p. 212). in addition, the EG were informed in their first class that they would be taught using 
Suggestopedic methods, and no-one decided to drop out. Although the authors state that a questionnaire answered by the students revealed no knowledge of Suggestopedia, it is suggested that knowledge of the alleged superiority of these techniques was freely available on campus. GassnerRoberts has since publicly stated (at a seminar at Macquarie University attended by B. D.) that students fought to get into her class because her students obtained reliably good results. The expectancy created by this, and the teacher's expectations, may have resulted in a self-fulfilling prophecy (Biggs \& Telfer, 1987) and the special arrangements may have resulted in a Hawthorne effect. (This is the phenomenon where any "special" procedure given to a selected group results in an improvement in performance - Turney \& Robb, 1971.)

\section{Drop-out rate}

Two other factors may also have affected the experimental outcome.

One is the large drop-out rate from the CO-D. Of the 22 students who started the course, only eight students finished. It is unclear whether this reflects differences between day and evening students, the already existing impact of demand characteristics, frustration at not being in the 'special' class, or students estimating their progress. Nonetheless, it is indicative of inequality and potential bias.

\section{Material presentation, Format and Amount}

The other factor which may have affected experimental outcome was the weekly, unannounced, self-correcting quizzes given to the EG throughout the year. This meant that EG students had the material presented to them again, in a different format and had to retrieve the information from memory. The EG consistently received more material, presented in various forms, ie. reading, discussions, and singing. The presentation of additional material is indicative of teacher expectations (Good \& Brophy, 1980). Students, told they are being given additional material to learn because they have already covered the course material, have expectations too. The increase in self-esteem, and ego involvement could result in increased motivation.

Those factors, rather than Suggestopedic techniques per se, may be responsible for the difference in performance between the EG and the control groups.

Despite the implementation of a full Suggestopedia program and a teacher trained and experienced in its application, the experimental group increased their performance over the control groups by only 9\%, well below the tenfold increase claimed by Lozanov (1978). The Hawthorne effect and the self-fulfilling prophecy could readily account for an increase of this size. 


\section{Unmatched experimental time}

A number of studies fail to match experimental time for control and experimental groups (Schuster \& Martin, 1980; Gamble, el al., 1982; Wagner \& Tilney, 1983). In the Gamble et al. study, the dependent variable was creativity. The experimental group was asked to practise relaxation at home each day. During the relaxation it is possible subjects would think about the task and generate ideas. This may have disadvantaged the control group.

Experimental subjects in the Wagner \& Tilney (1983) study received a taped relaxation procedure which lasted 15 minutes. The control group were asked to sit and relax for five minutes. The rationale for not matching experimental time for all three groups was that previous studies had shown that without directed relaxation, subjects found the procedure tedious. It would perhaps have been more appropriate to have given the control subjects a filler task so that experimental time was matched.

In the Schuster \& Martin (1980) study, experimental time was not matched across subjects. Those given suggestion underwent a Gestalt disintegration procedure, while subjects given no suggestion went straight into the next phase. This happened eight times during the experiment and, while the exact length of the Gestalt procedure is not given, it must have resulted in a substantial increase in experimental time for these subjects.

\section{Concluding Comments}

A number of features of the literature may be operating to produce publication of favourable rather than unfavourable evaluations of SALT. First, the most obvious place for publication of relevant studies is the Journal of the Society for Accelerated Learning and Teaching. Assuming (and there is no reason not to) that this journal attempts to maintain objective review, its title and its likely readership suggest that it is more likely to attract submission of positive findings than negative findings. Second, even with attempted objectivity, in general negative results are less likely to be published ( see Furedy, 1978). Third, the reluctance of the Bulgarian government to release full details of results leaves open the possibility that potentially damaging details are being withheld. The absence of full details disallows proper scientific evaluation.

The published studies are generally methodologically flawed. When no control group exists, or subjects in the groups are not given equal teacher attention, or equal time in the experimental situation, or the groups differ in important respects to begin with, no relevant legitimate conclusions can be drawn from the outcomes. Unfortunately, this applies to many reported studies. 
Results of the methodologically superior studies indicate that a number of individual components of the SALT technique are of doubtful value. Nonetheless, logical reason exists to expect the visualisation and synchronised breathing to aid learning. It is also possible that relaxation has an impact on learning and recall, which may vary with features of the subjects and the task employed. The latter possibility, along with other factors which vary greatly from study to study (duration of learning, instructor experience) may account for much of the variability of study outcomes.

Consistent with Palmer's (1985) conclusions, the published methodologically sound studies have produced more positive than negative results. thus, SALT may contain some potentially valuable techniques. However it is not clear whether this positive impression arises from publication bias, a technique which as a package is valuable, or a technique which contains some components which have already been established to be of value (e. g. visualisation). furthermore, it would appear that the more experienced (and more committed) salt teachers in long duration programs are more likely to report positive results. Therefore, the application of SALT techniques to the business and consulting world is of doubtful value until more is known about the underlying causes of the reported positive results. Nonetheless, the technique has sufficient potential to deserve continued, but methodologically rigorous, evaluation.

\section{References}

Alexander, L. (1982). Some preliminary experiments with SALT techniques: music and exercise, paired-words and narrative word-types and meaning checks. Journal of the Society for Accelerated Learning $\mathcal{E}$ Teaching, 7(1), 41-47.

Applegate, R. (1983). Accelerating learning potential. Paradise, CA: Paradise School District. Project Report, 7pp.

Bancroft, W. J. (1976). Suggestology and suggestopedia: the theory of the Lozanov Method. Journal of Suggestive-Accelerative Learning \& Teaching, 1(3), 187-216.

Baron, R. A. \& Byrne, D. (1984). Social Psychology. 4th Ed. Allyn \& Bacon, Boston.

Biggers, J. \& Stricherz, M. (1976). Relaxation and suggestion in a Recognition task. Journal of Suggestive-Accelerative Learning \& Teaching, $1(2)$.

Biggs, J. R. \& Telfer, R. (1987). The Process of Learning. Prentice Hall Australia, Melbourne.

Bordon, R. B. \& Schuster, D. H. (1976). The effects of a suggestive learning climate, synchronised breathing and music on the learning and retention of Spanish words. Journal of Suggestive-Accelerative Learning $\mathcal{E}$ Teaching, 1(1), 27-40. 
Bower, G. H. (1972.). Mental imagery and association learning. In L. W. Gregg (Ed). Cognition in Learning and Memory. J. Wiley \& Sons, NY.

Bugelski, B. R., Kidd, E. \& Segman, J. (1968). Image as a mediator in onetrial paired associate learning. Journal of Experimental Psychology, 76, 6973.

Caskey, O. (1976). Suggestopedic research in Texas. Journal of SuggestiveAccelerative Learning \& Teaching, 1, 350-359.

Ferguson, E. D. (1976). Motivation: An experimental approach. Holt, Rinehart \& Winston, NY.

Furedy, J. J. (1978). Negative results: Abolish the name but honour the same. In J. P. Sutcliffe (Ed.), Conceptual Analysis and Method in Psychology. Sydney University Press, Sydney.

Galyeau, B. C. (1982). The use of guided imagery in elementary and secondary schools. Imagination, Cognition, and Personality, 2, 145-151.

Gamble, J., Gamble, D., Parr, G. \& Caskey, O. (1982). The effects of relaxation training and music on creativity. Journal of the Society for Accelerated Learning \& Teaching, 7(2), 111-121.

Gassner-Roberts, S. \& Brislan, P. (1984). A controlled, comparative and evaluative study of a suggestopedic German course for first year university students. Journal of the Society for Accelerative Learning $\mathcal{E}$ Teaching, 9(3), 211-233.

Good, T. L. \& Brophy, J. F. (1980). Educational Psychology. 2nd Ed. Holt, Rinehart \& Winston, NY.

Jacobson, E. (1938). Progressive Relaxation. University of Chicago Press, Chicago, Ill.

Johnson, P. L. (1982). The effect of group relaxation exercises on 2nd and 6th grade children's spelling scores. Journal of the Society for Accelerated Learning \& Teaching, 7(3), 239-253.

Johnson, D. L. \& Spielberger, C. D. (1968). The effect of relaxation training and the passage of time on measure of state and trait-anxiety. Journal of Clinical Psychology, 24, 20-23.

Lozanov, G. (1978). Suggestology and Outlines of Suggestopedy. Gordon \& Breach, NY.

Martin, D. J. \& Schuster, D. H. (1977). The interaction of trait anxiety and muscle tension in learning. Journal of Suggestive-Accelerative Learning $\mathcal{E}$ Teaching, 7(1\&2), 63-67.

Ostrander, S. \& Schroeder, L. (1979). Superlearning. Souvenir Press (Aust.) Pty. Ltd., Melbourne.

Paivio, A. (1971). Imagery and Verbal Processes. Holt, Rinehart \& Winston, NY.

Paivio, A., Yuille, J. C. \& Madigan, S. A. (1968). Concreteness, imagery and meaningfulness values for 925 nouns. Journal of Experimental Psychology Monograph Supplement, 76(No. 1, Part 2), 1-25.

Palmer, L. L. (1985). SALT with learning disabled and other special need students: a literature review and meta-analysis. Journal of the Society for Accelerated Learning \& Teaching, 10(2), 99-129. 
Racle, G. (1976). The key principles of suggestopedia. Journal of SuggestiveAccelerative Learning \& Teaching, 1(3), 149-160.

Rosenthal, R. \& Jacobson, L. (1968). Pygmalion in the classroom. Holt, Rinehart \& Winston, NY.

Schuster, D. H. \& Gritton, C. E. (1986). Suggestive Accelerative Learning Techniques. Gordon \& Breach, NY.

Schuster, D. H. \& Martin, D. J. (1980). The effect of biofeedback-induced tension or relaxation, chronic anxiety, vocabulary easiness, suggestion and sex of subject on learning rare English words. Journal of the Society for Accelerated Learning \& Teaching, 5(4), 275-287.

Schuster, D. I l. \& Miller, T. M. (1979). The effect of active dramatic presentation, passive review with music, practice sentence making, word list difficulty and sex of subject on learning rare English words. Journal of Suggestive-Accelerative Learning \& Teaching, 4(1), 32-49.

Schuster, D. H. \& Mouzon, D. (1982). Music and vocabulary learning. Journal of the Society for Accelerated Learning \& Teaching, 7(1), 82-107.

Scovel, T. (1979,). Review of suggestology and outline of suggestopedy. TESOL Quarterly, 13, 255-266.

Shaffer, D. (1979). The Lozanov Effect: a scientific explanation. Journal of Suggestive-Accelerative Learning \& Teaching, 4 (3), 177-187.

Spielberger, C. D., Gorsuch, R. L. \& Lushene, R. (1968). Self-Evaluation Questionnaire. Palo Alto, CA: Consulting Psychologist Press.

Stein, B. L., Hardy, C. A. \& Totten, H. (1982). The use of music and imagery to enhance and accelerate information retention. Journal of the Society for Accelerated Learning \& Teaching, 7(4), 341-356.

Turney, B. \& Robb, G. (1971). Research in Education: An Introduction. Dryden Press, Hinsdale, Ill.

Wagner, M. J. \& Tilney, G. (1983). The effect of "superlearning techniques" on the vocabulary acquisition and alpha brainwave production of language learners. TESOL Quarterly, 17(1), 5-17.

Zeiss, P. A. (1984,). A comparison of the effects of superlearning techniques on the learning of English as a second language. Journal of the Society for Accelerated Learning \& Teaching, 9(2), 93-101.

Please cite as: Dipamo, B. and Job, R. F. S. (1991). A methodological review of studies of SALT (Suggestive-accelerative learning and teaching) techniques. Australian Journal of Educational Technology, 7(2), 127-143. http: / / www.ascilite.org.au/ajet/ajet7/dipamo.html 